\title{
A case report of ABPA, cystic fibrosis and asthma treated with omalizumab
}

\author{
JA Mazza1*, J Lewis ${ }^{2,3}$, Tracy Gooyers ${ }^{3}$ \\ From 3rd WAO International Scientific Conference (WISC) 2014 \\ Rio de Janeiro, Brazil. 6-9 December 2014
}

\section{Introduction}

In Canada the use of Omalizumab is restricted to patients with moderate to severe allergic asthma. However there are some cases reports showing its effectiveness in other conditions like chronic urticaria, ABPA and patients with nasal polyps and asthma. Although there are also reports of using omalizumab in patients with cystic fibrosis and ABPA, there are not controlled trials confirming their efficacy.

\section{Case report}

A seventeen year old girl diagnosed with Cystic Fibrosis at the age of 6 and subsequently developed ABPA at the age of 15 but also had clear evidence of bronchial asthma confirmed by history and spirometry. She also had significant environmental allergies.

The diagnosis of ABPA was confirmed based on 5 or more criteria accepted by international committees and Cystic Fibrosis by genetic testing. She also had pancreatic insufficiency consistent with Cystic Fibrosis.

Because her condition was gradually deteriorating requiring despite the use frequent courses of antibiotics, prednisone and admissions to the hospital, it was decided to place her on omalizumab in August 2012. The dose based on her weight and total IgE was $225 \mathrm{mg}$ every 2 weeks.

\section{Results}

She felt better subjectively within two months after she was placed on omalizumab and after almost 2 years of treatment she had a significant improvement in all objective parameters including lab investigations, decreased need for steroids, antibiotics, admissions to the hospital and quality of life. She has not had any adverse reactions.

\section{Summary}

It is known that Cystic Fibrosis together with ABPA will induce a more significant deterioration of the lung function than either alone and seriously interferes with quality of life. However, it appears that adding omalizumab to her current treatment has had an overall significant benefit that was sustained over 2 years.

The authors are aware that although it is unlikely that there will be RCT in this unique group of patients, case reports such as the one presented, might encourage others to follow the same approach in specific patients.

\section{Consent}

Written informed consent was obtained from the patient for publication of this abstract and any accompanying images. A copy of the written consent is available for review by the Editor of this journal.

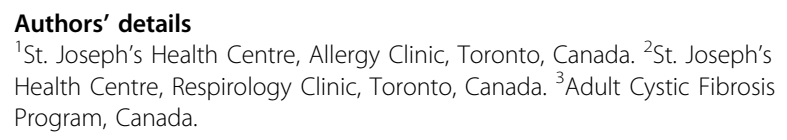

Published: 8 April 2015

doi:10.1186/1939-4551-8-S1-A86

Cite this article as: Mazza et al:: A case report of ABPA, cystic fibrosis and asthma treated with omalizumab. World Allergy Organization Journal 2015 8(Suppl 1):A86.

${ }^{1}$ St. Joseph's Health Centre, Allergy Clinic, Toronto, Canada

Full list of author information is available at the end of the article 